\title{
시민사회가 바라는 ODA 백서 방향
}

\author{
윤 지 영 (ODA Watch, 정책기획팀장)
}

\section{목 차}

I . 들어가며

II. 시민사회가 바라는 한국 ODA 백서 방향

1. 인류의 보편적 가치 실현을 위한 비전을 제시하는 백서

2. 한국 국제개발협력의 책무성과 투명성을 높이는 백서

III. 맺으며

\section{$\mathrm{I}$. 들어가며}

최근 한국 정부는 국제개발협력에 대한 법적·제도적 틀을 마련하고자 꾸준히 노력해왔다. 2010년 1월「국제개발협력기본법(이하 기본법)」이 제정되고 이를 뒷받침 하는 전략으로「국제 개발협력 선진화방안(이하 선진화방안)」이 같은 해 10월 수립되었다. 2012년 9월에는 국제개 발협력선진화를 위한 실천전략으로써「한국형 ODA 모델 추진방안」이 수립되기도 했다. 불과 5년 전 OECD 개발원조위원회(Development Assistance Committee, 이하 DAC) 가입을 앞두 고 받았던 2008년 OECD DAC 특별동료검토에서 국제개발협력 전반을 포괄하는 법적·정책적 
체계가 부재하다는 평가를 받았던 것을 상기하면, 오늘날 관련 법령과 전략에 따라 추진체계 를 개선해 나가고 있는 것은 상당한 변화이다.

법적제도적 체계 수립에 대한 인식은 국제사회의 평가에서도 찾아볼 수 있다. 지난 해 한국 은 2010년 DAC 회원국으로 가입한 이후 처음으로 정기 동료검토를 받았다. 심사단은 검토 결 과 보고서를 통해 기본법과 선진화방안 수립 등으로 한국 국제개발협력의 전반적 체계가 정비 되고 예산계획 관리의 명확성이 높아졌음을 평하고 있다. 그러나 한편에서는 관련 의사결정 기준이 불분명하고 주요 정보에 대한 접근성이 낮음을 지적하면서 다양한 이해관계자들과의 쌍방향 소통을 강화할 것을 주문했다. 아울러 정부의 노력을 국민들이 공감하고 지지할 수 있 도록 관련 정보를 적극적으로 공개할 것을 권고했다.

정부는 위에서 언급한 사항을 포함, 2012년 동료검토 결과와 권고사항을 향후 국제개발협력 정책 개선의 이정표로 적극 활용하여 주요 과제 개선에 힘을 쏟기로 했다. 이에 지난 2월 15 일 에 열린 제 15 차 국제개발협력위원회에서 "OECD/DAC 개발협력 정책-집행 평가 결과 및 활 용방안"과 “국제개발협력(ODA) 주요 현안”을 의결하여 주요 ODA 선진화 과제 추진방안을 이 행하기로 결정했다. 금년 내에 추진하기로 채택한 주요 과제 중 하나는 ODA 통합홍보계획으 로, 요지는 ODA에 대한 통합홍보 전략과 체계를 마련하여 홈페이지, 미디어 등을 활용해 국 민들에 대한 ODA 홍보를 강화하겠다는 것이다. 그 배경으로 2015년까지 국민총소득 대비 $\mathrm{ODA}$ 비율을 $0.25 \%$ 로 늘리기로 한 목표를 달성하려면 국민적인 지지 확보와 공감대 형성이 필수적임을 들고 있다.

통합홍보계획은 $\mathrm{ODA}$ 의 비전과 정책, 사업성과를 쉽고 투명하게 제공하고 소통을 강화하여 국민들의 ODA에 대한 인지도와 이해도를 높이는 것을 목표로 하고 있다. 이를 실현하기 위한 방안 중 하나가 $\mathrm{ODA}$ 백서 발간이며, 한국 $\mathrm{ODA}$ 의 비전과 정책, 전략과 성과 등을 $\mathrm{ODA}$ 관련 자들과 일반국민들에게 종합적·체계적으로 보고하는 것을 목표로 한다. 한국 $\mathrm{ODA}$ 의 비전과 목표, 주요 전략과 추진체계, 예산계획, 국제사회와의 공조, 사업성과 등이 백서의 주요 내용 으로 담길 예정이다. 정부는 백서가 발간되면 투명성·책임성 관련 예산자료와 개발원조 성과 당면과제에 초점을 둔 종합보완문서가 결여되었다는 $\mathrm{OECD} \mathrm{DAC} \mathrm{동료검토의} \mathrm{지적} \mathrm{사항도} \mathrm{개}$ 선이 가능할 것으로 전망하고 있다. ${ }^{1)}$

한국은 약 50 년간 국제사회의 원조를 받던 나라였다. 2000년도에 이르러서야 OECD DAC 1) 국제개발협력위원회, 제15차 국제개발협력위원회 의결안건 제15-3호 국제개발협력(ODA) 주요 현안(안), $\mathrm{p} 81$ 
수원국 리스트에서 제외되어 순수 원조 공여국으로 지위가 바뀌었다. 1960 년대부터 원조 지원 에 참여해왔으나 본격적으로 뛰어든 것은 대외경제협력기금 설치(1987)와 한국국제협력단 설 립(1991) 이후이다. 불과 20여년의 짧은 원조 공여경험이지만 단기간에 원조규모를 확대하고 국제규범을 적용하며 원조효과성을 높이고자 노력해온 것이 사실이다. 더불어 DAC 가입으로 개발도상국의 빈곤문제를 포함해 지구적 과제 해결에 더욱 적극적으로 기여해야 할 책임을 가 지게 되었다. 이러한 맥락 속에서 만들어지게 된 ODA 백서는 한국의 개발협력 참여에 대한 국민들의 지지 기반을 마련하고 한국 국제개발협력의 미래 비전을 제시하는 계기가 되어야 한다.

이 글에서는 $\mathrm{ODA}$ 백서가 한국 국제개발협력의 새로운 비전과 목적에 대한 사회적 합의를 구축하는 제도적 장치가 되어야 한다는 것을 주안점으로 이번 백서가 지향해야 하는 방향을 제안하고자 한다.

\section{II . 시민사회가 바라는 한국 ODA 백서 방향}

\section{1. 인류의 보편적 가치 실현을 위한 비전을 제시하는 백서}

백서란, 일반적으로 정부가 특정사안이나 주제에 대해 현상을 분석하고 미래를 전망하여 그 내용을 국민에게 알리고자 만든 보고서이다. 단순한 현황 분석이나 사실 열거 보다는 주제에 대한 철학과 위상을 담아 국민들이 공감할 수 있도록 하는 것이 핵심이다. 금년 말까지 수립될 예정인 $\mathrm{ODA}$ 백서는 한국 국제개발협력 역사상 처음으로 발간되는 것이니만큼 안팎으로 많은 주목과 관심을 받을 것으로 예상된다.

기본법이 우리나라 국제개발협력의 기본정신과 목표를 밝히고 있지만, 우리가 왜 다른 나라 를 도와야 하는지, 어떻게 도와야 하는지 등의 근본적인 질문에 일관되게 답할 수 있는 명확한 신념과 비전, 가치와 철학을 제시하지 못한 것은 태생적 과제로 남아있던 부분이다. 그러므로 이번 $\mathrm{ODA}$ 백서 발간은 한국 국제개발협력의 근본적인 가치와 철학에 대한 사회적 논의와 소 통을 촉진하는 계기로 중요한 의미를 가진다고 할 수 있다. 또한 점차 국제개발협력에 참여하 는 행위자들이 다양해지고 있는 현 시점에서, 원조효과성과 개발효과성 제고 차원에서도 우리 가 지향해야 할 일관된 최상위 목적을 제시하는 것은 반드시 필요하다. 
기본법 제 3 조 1 항에 따르면 한국의 국제개발협력은 개발도상국의 빈곤감소, 여성과 아동의 인권향상 및 성평등 실현, 지속가능한 발전 및 인도주의를 실현하고 협력대상국과의 경제협력 관계를 증진하며 국제사회의 평화와 번영을 추구하는 것을 기본정신으로 한다. 최근에는 여성 과 아동뿐만 아니라 장애인의 인권향상 대목이 추가되기도 했다. 전체적으로는 한국 국제개발 협력의 목적이 “인류의 공동번영과 세계평화의 증진에 기여”하는 것으로 명시되어 있지만 “협 력대상국과의 경제협력관계 증진”이라는 목표도 함께 제시하고 있다. 이는 개발도상국의 빈곤 문제 해결과 지속가능한 발전이라는 국제개발협력의 가장 보편적인 목적과 다소 동떨어지는 내용이다. 또한 기본법과 동시에 무·유상 원조를 규율하고 있는 한국국제협력단법과 대외경제 협력기금법에서는 개발도상국의 빈곤감소 보다는 우리나라와의 우호협력관계를 증진하는 것 을 우선시하고 있어 기본법이 한국이 원조를 하는 이유에 대한 충분한 성찰 없이 기존의 두 법 령을 형식적으로 조합한 것에 불과한 것이 아니냐는 비판도 존재한다. 기본법 제정 당시 시민 사회에서는 한국 원조의 목적과 정책 방향을 혼동시킬 '경제협력' 항목을 삭제할 것을 요청하 기도 했다. ${ }^{2)}$

한국 국제개발협력이 빠른 시간 내에 급속히 성장하면서 정작 '한국이 왜 다른 나라를 도와 야 하는가?', '우리는 왜 개발협력에 참여해야 하는가?' 의 근본적인 질문에 대한 사회적 논의 는 부족했다. 일관적으로 합의된 목적이 없다보니 개발협력 사업들이 행위자별로, 지역마다 제각각으로 추진되고 있는 실정이다. 개발협력 사업을 하기에 앞서 가장 중심으로 세워야 할 목적과 원칙에 대한 합의 없이 사업을 실행해온 관습과 인식이 기본법에도 그대로 반영되었 다. 기본법 제정 이후에도 한국 정부는 개발도상국 지원을 국제사회의 일원으로서 다해야 할 인도적 책무임과 동시에 국익 제고를 위한 수단으로 인식하고 있음을 공공연하게 밝혀왔다.

하지만 ODA 백서 발간을 계기로 한국 국제개발협력의 비전과 목적을 새롭게 구상해야 할 필요가 있다. 국가, 시민사회, 기업 등 행위자별로 각자의 동기와 목표를 달성하고자 개발도상 국을 지원하는 것이 수단으로 남용되어서는 안 된다. 개발협력은 공존을 위한 전 지구적 책임 이자 그 자체가 목적이다. 따라서 인간의 존엄성 보장 등 인종, 민족, 종교, 정치 신념, 동서고 금을 막론하고 공통으로 합의한 인류의 보편적 가치 실현이 한국이 개발협력에 참여하는 최상 위 목적이 되어야 한다. 국익 제고나 대상국가와의 우호협력관계가 증진되는 것은 목적이 아 닌 기대효과로 조정될 필요가 있다. 이미 우리보다 훨씬 앞서 개발협력에 참여해온 영국, 스웨 덴, 독일 같은 나라들은 오랜 경험과 시행착오를 통해 자국의 원조 목적을 인권 신장, 지구촌

2) ODA Watch, 한국YMCA전국연맹, 참여연대, 지구촌빈곤퇴치시민네트워크(2009.12.4) 공동성명: 국제개발협력기본법 (안)의 전면적인 재검토를 요청한다 
의 빈곤감축과 불평등 해소 등 보다 보편적 가치 실현을 위한 것으로 전환해 나가고 있다.

실제로 영국의 경우 1997년 DFID(Department for International Development) 설립 이전 까지는 국가 안보와 경제적 이익 등 국내 이익 추구를 원조 목적으로 두고 있었다. 그러나 DFID 설립과 함께 추진한 원조개혁 과정에서 발간한 백서3)를 통해 영국의 원조가 빈곤 퇴치 와 가난한 이들에게 혜택이 돌아가는 경제성장을 장려하는 것을 목적으로 이루어져야 함을 밝 혔다. 이를 뒷받침하고자 조건부 원조를 모두 폐지하고 비구속성 원조를 전면 실시하는 등 정 책적 변화를 시도했다. 뒤이어 2009년까지 세 차례 더 백서를 발간했는데(2000, 2006, 2009) 이들 백서에서도 빈곤 퇴치라는 큰 목적을 중심으로 두고 그 목적을 이루는 구체적인 목표들 을 제시하고 있다.

영국과 유사하게 국내적 이익을 고려하여 원조를 제공해온 호주의 경우에도 백서 수립 과정 을 통해 원조 목적과 방향을 조정해왔음을 알 수 있다. 호주의 개발협력은 전통적으로 국익의 최대화와 지구적 차원의 성장을 동시에 꾀해왔다. 그러나 국익과 연계되는 개발협력 사업은 국제사회 공조의 궁극적인 목적인 빈곤 감축을 저해할 수 있다는 대내외의 우려를 진지하게 검토하여, 이후 백서(2006)와 정책 문서 수립을 통해 원조 목적을 빈곤 감소에 초점을 두는 것 으로 설정했다. 지구적 빈곤이 줄어드는 것이 자국의 국익과 상통한다고 밝히며 보다 적극적 으로 파트너십에 기반을 둔 개발협력을 지향할 것을 강조하고 있다. ${ }^{4)}$

이밖에도 스웨덴의 경우에는 '가난한 사람들의 삶의 질을 향상시키는 자조노력 지원', 독일 은 '지구적 빈곤 감축과 구조적 결핍 해소, 인권 증진과 평화 구축', 벨기에는 '지속가능한 인 간 개발을 위한 빈곤퇴치', 캐나다는 '빈곤감축, 인권 증진, 지속가능한 발전 지원'을 원조 목 적으로 채택하고 있다. ${ }^{5)}$

금년은 바깥으로 새천년개발목표(MDGs) 달성 시점을 2 년 앞두고 $\mathrm{MDGs}$ 이후 국제사회가 준수해야 할 Post 2015 프레임워크에 대해 본격적인 논의가 이루어지고 있는 시점이다. 국내 적으로는 백서는 아니지만 최근 3 년간 이루어진 개발협력사업의 정책목표와 전략을 담고 있는 선진화방안과 분야별 기본계획(2011-2015)의 중간 점검이 필요한 시기이기도 하다. 한국 정 부는 ODA 백서를 수립하는 과정에서 국제담론의 주요 맥락을 신중히 검토하여 한국 개발협력

3) DFID(1997), Eliminating World Poverty: A Challenge for the 21st Century

4) AusAID(2006), Australian Aid: Promoting Growth and Stability

5) OECD DAC(2009), Managing Aid Practices of DAC Member Countries 
이 국제규범을 어떻게 반영할 것인지 명확히 제시해야 한다. 또한 2015 년 이후 국제사회가 공 동으로 준수해야 할 개발목표를 달성하는데 우리가 어떻게 기여할 것인지를 구체적으로 밝혀 야 한다.

이러한 흐름 속에서 이번 ODA 백서를 한국 국제개발협력의 철학과 이념, 가치와 원칙을 재 정립하는 계기로 활용해야 한다. 이에 소위 '한국형 원조'라고 불리는 우리식 개발 경험 전수 를 위한 원조, 한국 기업의 해외 시장 진출과 자원 확보를 위한 원조 등 단기적 국익 추구의 원조 관행에서 벗어나 국제사회가 선경험을 통해 제시하고 있는 원칙과 가치들을 반영해야 한 다. 빈곤 감축과 지속가능한 발전, 인권 향상과 구조적 불평등 해소 등 보편적 가치를 위한 개 발협력이 중심이 되어야 할 것이다. 원조 목적이 바뀌면 그동안 국제사회로부터 취약하다고 비판 받아온 모든 원조의 비구속화, 최빈국과 고채무국에 대한 유상원조 전면 폐지 등의 정책 도 과감히 도입할 수 있을 것이다.

나아가, 정부는 이번 ODA 백서 발간을 단순한 성과 홍보 수단으로 간주해서는 안 된다. '우 리나라에도 어려운 사람들이 많은데 왜 우리가 다른 나라를 지원해야하는가?', '한국 원조의 최상위 목적은 무엇인가?', ‘한국 원조는 누구와, 무엇을 중점적으로 일해야 하는가?' 등과 같 은 가장 기초적인 질문을 통해, 지난 20여 년간 규모 확대를 중심으로 성장해온 한국 국제개 발협력의 실태와 도전과제를 진솔하게 성찰하는 기회로 삼아야 한다. 아울러 기본법과 더불어 한국 개발협력의 근간이 되는 문서이니 만큼, 산출 결과를 만들기에 급급하기 보다는 시민사 회를 포함한 다양한 주체들과 적극적으로 소통하며 다각도의 논의가 이루어질 수 있도록 보장 해야 할 것이다.

\section{2. 한국 국제개발협력의 책무성과 투명성을 높이는 백서}

국제개발협력은 국민의 기여를 통해 지구촌 공공재를 확대하는 일이다. 따라서 국민들의 지 지기반 없이는 추진할 수 없다. 앞서 살펴본 유럽 국가들의 대외원조 목적을 상기하면 이들 나 라 국민들은 원조가 자국의 이익을 위한 것이 아니라 개발도상국의 인권 향상과 지속가능한 발전, 분쟁 해결과 평화 구축을 위해 실시되어야 한다는 정부 정책을 지지하고 있음을 추측할 수 있다. 영국을 비롯한 유럽 국가들은 오랫동안 개발협력 정책에 대한 국민적 공감대와 지지 기반을 확보하고자 공교육 내에 지구시민교육을 포함하는 등 국민 의식 제고 교육을 실시해 오고 있다. ${ }^{6)}$ 
그러나 국제개발협력에 대한 우리 국민의 인지도는 낮은 편이다. 대외경제정책연구원이 2011년 실시한 ODA에 대한 국민인식 조사 결과, 한국 정부의 ODA 시행에 대해 국민의 절반 이 잘 모르거나 전혀 모른다고 답했다. 7) 또한 $\mathrm{MDG}$ 에 대해 전혀 들어본 적 없다는 응답이 $59.1 \%$ 로 나타났다. 부산 세계개발원조총회, G20 서울정상회의 등 주요 국제회의 유치로 한국 의 개발협력 노력을 국제사회에 알리는 노력을 한 것에 비하면 국민들의 관심도와 인식 수준 은 크게 낮다고 할 수 있다. 그러므로 국민의 이해와 인식을 높이기 위한 노력이 확대될 필요 가 있다.

개발협력 관련 정보 접근성 측면에서도 국민 인지제고 노력이 절실하다. 동 설문조사 결과, 관련 정보를 접한 경험이 있는 응답자는 $52.4 \%$ 에 불과했다. 하지만 정보를 접한 경험이 있는 경우 관련 사항에 대한 인지도가 높은 것으로 나타나 개발협력 정보 제공이 인지도를 높이는 데 긍정적으로 작용함을 알 수 있다. 국민의 관심이 정부의 정책을 지지하고 실질적인 원조정 책 개선과 담론 형성에 기여할 수 있도록 하려면 개발협력 관련 주요정보 제공의 폭을 넓히고 참여할 수 있는 논의의 장이 다양하게 마련되어야 한다.

이런 측면에서 $\mathrm{ODA}$ 백서는 국민과 소통하고 개발협력에 대한 사회적 논의를 촉진하는 계기 로 유용하게 활용될 수 있다. 2006년에 첫 백서를 발간하고 금년 5월 두 번째 백서를 발간한 아일랜드의 사례는 우리 백서 수립 과정에 참고할 교훈을 제공한다. 아일랜드 정부는 두 번째 백서를 수립하기에 앞서 첫 번째 백서에 대한 재검토 과정(The White Paper Review Process)을 통해 아일랜드 개발협력에 대한 전반적인 평가 기회를 가졌다. 2011년 6월부터 약 1 년간 진행된 재검토 과정 기간에 165 건의 제안서가 제출되었고 100 건이 넘는 협의 회의가 열 렸다. ${ }^{8)}$ 아일랜드 정부는 유사 공여기관(like-minded donor), 다자기구, 협력대상국 뿐만 아 니라 주제별로 시민사회단체들과 폭넓은 협의를 갖고 현재 아일랜드가 직면하고 있는 도전과 제를 평가하고 향후의 핵심 개선과제를 도출하고자 노력했다.

특히 아일랜드 시민사회는 재검토 과정이 아일랜드 개발협력의 책무성과 투명성을 향상시 키는 핵심적인 수단임을 인식하고 시민사회와의 긴밀한 협력이 강화되어야 함을 강조했다. 또 한 아일랜드 개발협력의 목적과 비전에 대한 공동의 합의를 구축하는 계기로 활용할 것을 요 구했다. 아일랜드 시민사회는 두 번째 백서가 발간되자마자 보도 자료를 발표하여 정부가 천

6) Owen Barder(2010), Reforming Development Assistance: Lessons from the U.K. Experience

7) 대외경제정책연구원(2011), ODA에 대한 국민인식조사 결과 및 국제비교

8) The Irish Association of Non-Governmental Development Organisation(2013.05.08), Ireland's new Development Policy-A word count analysis 
명한 개발협력의 목적과 방향에 큰 지지를 표했다. 이들은 백서가 국제사회 공동문제 해결에 대한 아일랜드 국민들의 도덕적 책임의식을 반영하고 있으며 아일랜드 원조가 모든 인간의 존 엄한 삶 실현에 기여하는 것을 목적으로 해야 함을 명확히 제시하고 있다고 평했다. ${ }^{9)}$ 아일랜 드 정부가 이 같은 시민사회의 지지를 받을 수 있는 이유는 아일랜드가 추구해야 할 개발협력 목적에 대해 수많은 논의를 거쳐 공동의 합의를 이끌어 낸 노력이 있었기 때문이다. 주요 정책 결정 과정에 시민사회를 비롯한 국민들의 참여와 개입을 대폭 강화하는 것이 대국민 이해와 지지를 고취할 수 있는 방안임을 시사하는 대목이다.

영국의 경우에도 2009 년 발간된 백서 수립 과정에서 약 3 개월의 대국민 협의 절차를 가지 고 다양한 이해관계자들의 의견을 수렴했다. 영국 정부는 협의과정에서 중점적으로 다루어야 할 핵심 주제를 명시한 가이드라인 문서(DFID Consultation Document)10)를 제공하여 효과 적인 협의가 이루어질 수 있도록 했다. 문서에는 영국 개발협력 관련 현황과 맥락, 영국 정부 가 구상하고 있는 백서 초안과 4대 중점 분야를 담고 있다. 아울러 영국이 지향할 정책 형성에 국민들의 경험과 지식, 지혜를 필요로 한다고 명시하여 다양한 주체들이 협의 과정에 참여할 수 있도록 독려했다. 실제로 당시 영국 국민을 비롯해 국내외 관련 기관, 시민단체로부터 받은 제안서가 2500건이 넘었다. ${ }^{11)}$ 이러한 사실을 통해서도 백서 수립과정이 정부 정책에 대한 대 국민 관심을 높이고 참여를 확대시키는 촉매제 역할이 될 수 있다는 점을 확인할 수 있다.

그러나 한국 정부의 ODA 백서 발간 계획을 보면 정부가 ODA 백서 수립을 단순한 홍보 수 단으로 인식하고 있는 것이 아닌지 우려 된다. 새로운 비전과 목적에 대한 폭넓은 협의를 가지 기보다 지금까지 이루어 온 사업성과를 홍보하는 것에 중점을 두고 있다. 금년 말 발간을 목표 로 하고 있으나 이미 한해의 절반이 지난 지금까지 시민사회와의 협의나 대중 의견 수렴을 위 한 공식적인 계획도 밝히지 않고 있다. 한국이 ODA 백서를 발간한다는 사실을 아는 국민들도 많지 않을 것이다. 이로 말미암아 다양한 이해관계자들과의 협의 과정을 거치지 않고 소수의 민간 자문단의 의견을 수렴하는 것에 그칠 가능성이 크다. 한국 최초의 ODA 백서가 겉보기에 화려한 업적 위주의 번지르르한 국정 홍보 자료가 되는 것은 아닌지 염려스럽다.

정부는 이번 ODA 백서 수립과정을 오랫동안 안팎으로 지적받아온 과제인 '투명성·책무성 부족'을 개선할 수 있는 기회로 인식하고 보다 적극적으로 소통하는 노력을 기울여야 한다. 작

9) The Irish Association of Non-Governmental Development Organisation(2013.05.02), Press Release: Irish NGOs welcome Government's reaffirmation that Ireland's future depends on a stable and fairer world 10) DFID(2009), Eliminating World Poverty: Assuring our Common Future, A consultation document(2009) 11) BOND(2009), DFID Consultation Process 
성 과정에서 정부 관계자뿐만 아니라 시민사회, 학계, 민간과의 더 많은 열린 대화와 협력을 통해 국민들의 인식을 종합적으로 반영해야 한다. 그 결과로 과거의 낡은 원조관행들을 성찰 하고 성과뿐만 아니라 실패 경험에서 얻은 교훈을 진솔하게 밝히는 것도 필요하다. 궁극적으 로는 한국 국제개발협력이 추구해야 할 공동의 비전과 목적을 합의해나가는 최초의 대국민 참 여 제도 구축으로 발돋움해나가야 한다.

한국 국제개발협력의 주요 정책 결정과정에 국민들의 인식과 행동이 반영될 수 있도록 하는 것은 결국 협력대상국의 발전에 기여하는 것과 동시에 원조 자금 조성에 납세자로 참여하고 있는 국민들에 대한 책무를 다하는 것과 직결된다. 국민들의 관심과 참여가 높아지면 정부도 정책과 사업 실행에 대한 책무성을 높이지 않을 수 없을 것이다.

\section{III. 맺으며}

주지한 바와 같이 올해는 향후 한국 국제개발협력의 미래를 구상하기 위한 중요한 시기이 다. 기존에 수립한 정책과 전략이 제대로 이행되고 있는지 중간 점검을 요하는 시점이자 부산 글로벌 파트너십과 $\mathrm{OECD} \mathrm{DAC} \mathrm{동료검토} \mathrm{권고사항의} \mathrm{이행계획들이} \mathrm{구체적으로} \mathrm{마련되는} \mathrm{시점}$ 이기도 하다. 아울러 새로운 정부가 들어섰고 이에 따라 관련 기관들의 수장과 리더십의 변화 도 겪었다. 무엇보다 2015년까지 GNI 대비 ODA 비율을 $0.25 \%$ 까지 확대하기로 한 공약 달성 중간 지점에서 한국 국제개발협력이 보다 효과적으로 지구적 과제 해결에 기여할 수 있는 방 안을 고심하는 것이 필요하다. 이러한 맥락에서 한국 개발협력 역사상 최초로 수립될 ODA 백 서는 개발협력 정책과 정보에 대한 상세한 설명을 제공하는 것 이상의 의미를 가진다 할 수 있다.

따라서 $\mathrm{ODA}$ 백서 수립과정은 일부 $\mathrm{ODA}$ 관계기관과 전문가들만이 향유하는 정보공유의 장 이 되어서는 안 된다. 그동안 국제개발협력에 참여해 온 다양한 주체들이 자신들의 경험으로 배운 교훈과 성찰의 결과를 나누고 이들이 국내 개발협력 관련 모든 정책들과 연계될 수 있도 록 돕는 교량적 소통의 장이 되어야 한다. 여기서 이러한 소통 과정이 누구나 쉽게 접근하고 알 수 있도록 하는 것이 중요하다. 이를 통해 한국이 국제개발협력에 참여해야 하는 이유와 당 위성에 대한 국민적 공감대를 확보하고 원조 규모 확대에 대한 회의와 거부감을 줄여나갈 수 있을 것이다. 
또한 백서 수립 과정을 통해 다양한 주체들이 과거 한국의 개발성과를 냉철하게 재평가할 수 있도록 장려하여 한국 원조의 강점과 약점, 기회와 위협 요소들을 명확히 밝혀내야 한다. 향후 우리가 중점적으로 지원해야 할 지역과 분야, 협력해야 할 파트너를 정리할 수 있는 기회 가 될 수 있을 것이다.

가장 중요한 것은 앞서 재차 강조한 것처럼 인류의 보편적 가치 실현에 책임을 다하는 한국 국제개발협력으로 자리매김할 수 있도록 새로운 비전과 목적을 수립하는 일이다. 이를 위해 단순히 원조 규모를 늘리는 것뿐만 아니라 개발도상국의 발전에 영향을 미치는 모든 요소들을 고려한 총체적 접근이 필요하다. 궁극적으로는 개발을 위한 정책일관성을 높이고 개발협력에 대한 범정부차원의 정치적 의지와 실행 역량을 강화할 수 있는 방안을 제시해야 할 것이다.

정부는 금년을 시작으로 3 년 주기로 백서를 보완, 발전시켜 나갈 계획이다. 따라서 금년에 는 ODA 백서 수립 계획을 이해관계자들과 국민들에게 널리 알리고 다양한 의견 개진으로 참 여할 수 있도록 독려하는 것이 선행되어야 할 것이다. 이러한 사전 노력 없이 정부 주도로 'ODA 백서'라는 이름의 문서를 생산하는 것에만 치우친다면 백서가 지닌 본연의 의미를 찾기 어려울 것이다.

아무쪼록 이번 ODA 백서 발간 작업이 지구촌 이웃의 어려움을 나누고 지속가능한 발전에 기여하기 위한 국민의 뜻을 모아 진지하게 헤아리는 계기가 되기를 바란다. 국제개발협력이 국익을 위한 수단이 아니라 지구적 공공재로서 국민들의 선한 의지와 참여를 국가가 대신하여 실현하는 것이라고 생각한다면 우리 ODA 백서가 나아가야 할 방향이 명료하게 정리될 것이 다. 영국, 독일, 호주, 아일랜드, 캐나다, 일본 등 우리보다 앞장서 개발협력에 참여해온 나라 들이 겪은 시행착오를 반면교사(反面敎師) 삼아 한국 국제개발협력이 백서 수립을 통해 한층 성숙하고 책임 있는 자세로 지구적 과제 해결에 기여할 수 있기를 바란다. 


\section{참고문헌}

\section{〈국내문헌〉}

국제개발협력위원회(2013.02), 국제개발협력(ODA) 주요 현안(안), 제 15 차 국제개발협력위원회 의결안 건, 제 $15-3$ 호

대외경제정책연구원(2011), ODA에 대한 국민인식조사 결과 및 국제비교

ODA Watch, 한국YMCA전국연맹, 참여연대, 지구촌빈곤퇴치시민네트워크(2009.12.4), 공동성명 국 제개발협력기본법(안)의 전면적인 재검토를 요청한다

\section{〈국외 문헌〉}

AusAID(2006), Australian Aid: Promoting Growth and Stability

BMZ(2013), The German Government's 14th Development Policy Report, Development policy White Paper-Executive Summary

BOND(2006), DFID Consultation Process

BOND(2009), BOND Submission to the DFID White Paper 2009

DFID(1997), Eliminating World Poverty: A Challenge for the 21st Century, Cm. 3789

DFID(2009), Eliminating World Poverty: Assuring our Common Future, A consultation document Irish Aid(2011), Consultation paper For the Review of the White paper on Irish Aid Irish Aid(2013), One World, One Future: Ireland's Policy for International Development OECD(2008), Report of the Special Review of Korea

OECD(2009), Managing Aid Practices of DAC Member Countries

OECD(2012), Korea Development Assistance Committee(DAC) Peer Review 2012

Owen Barder(2010), Reforming Development Assistance: Lessons from the U.K. Experience The Irish Association of Non-Governmental Development Organisation(2011), Reveiw of Government White paper on Irish aid 2011-2012 
The Irish Association of Non-Governmental Development Organisation(2011), Mobilising for Transformation: Ireland's role in ending extreme poverty

The Irish Association of Non-Governmental Development Organisation(2013), Ireland's new Development Policy-A word count analysis

The Irish Association of Non-Governmental Development Organisation(2013), Press Release: Irish NGOs welcome Government's reaffirmation that Ireland's future depends on a stable and fairer world 